\title{
Perancangan Dan Pembangunan Aplikasi Rekrutmen Asisten Laboratorium Berbasis Mobile
}

\author{
Reynaldi Miftahudin Fauzi ${ }^{1}$ Finsa Nurpandi ${ }^{2}$ \\ Program Studi Teknik Informatika \\ Universitas Suryakancana \\ brorey524@gmail.comlinsa@unsur.ac.id
}

\begin{abstract}
Abstrak
Aplikasi Rekrutmen asisten laboratorium Fakultas Teknik Universitas Suryakancana dibangun atas dasar permasalahan yang sering terjadi saat proses pelaksanaan tahapan rekrutmen. Proses yang dimulai dari tahapan pengiriman berkas, memiliki hambatan jarak bagi peserta karena harus mengirimkan langsung ke laboratorium. Serta penyebaran informasi mengenai jadwal pelaksanaan tes serta pengumuman hasil seleksi yang dirasa masih kurang efektif menjadi alasan paling mendasar dalam pembangunan aplikasi ini. Aplikasi ini dibangun dengan menggunakan tahapan perancangan perangkat lunak Prototype. Dengan menggunakan dua platform yang berbeda yaitu Mobile dan web. Penggunaan REST API menjadi cara agar data yang berada di dalam satu Database yang sama dapat diakses dengan baik pada platform yang berbeda. Aplikasi Mobile akan digunakan oleh calon peserta rekrutmen, sedangkan aplikasi berbasis web digunakan oleh admin sebagai panitia pelaksana rekrutmen asisten laboratorium fakultas teknik Universitas Suryakancana.
\end{abstract}

Kata kunci: rekrutmen, Prototype, REST API, aplikasi Mobile, berbasis web

\section{Pendahuluan}

Fakultas Teknik khususnya Program Studi Teknik Informatika Universitas Suryakancana memiliki tiga laboratorium komputer yaitu Lab Dasar, Lab Multimedia, dan Lab Jaringan Komputer. Semua laboratorium komputer ini di kelola oleh Koordinator Laboratorium dan Asisten Laboratorium (Aslab). Bagi mahasiswa/i yang ingin menjadi Aslab harus mengikuti tiga tahapan utama diantaranya pengumpulan berkas, pelaksanaan tes, serta pengumuman hasil tes. Pelaksanaan tes dibagi menjadi beberapa tahap diantaranya tes psikotes, tes minatan, tes umum, wawancara dengan Aslab, dan wawancara dengan Dosen pengampu matakuliah berpraktikum. Perekrutan asisten dilakukan dalam satu tahun sekali dan biasanya menerima sekitar tujuh asisten baru.

Pada saat ini proses pengiriman persyaratan berkas perekrutan masih dilakukan secara manual artinya calon asisten mengirimkan langsung ke laboratorium dan pemberitahuan jadwal tes tulis dan wawancara masih menggunakan via SMS. Pengumpulan berkas persyaratan secara manual memiliki beberapa kendala dalam pelaksanaannya. Pertama, terkadang ada beberapa berkas yang tercecer maupun hilang ketika pemberkasan oleh panitia rekrutmen di laboratorium. Kedua, proses rekrutmen biasanya dilakukan ketika libur semester genap dan terkadang mahasiswa yang akan mendaftar harus menempuh jarak yang cukup jauh hanya untuk memberikan berkas persyaratan.

Pengumuman informasi jadwal tes serta pengumuman hasil rekrutmen masih menggunakan media SMS. Hal ini masih menyulitkan panitia rekrutmen karena harus mengirimkan informasi satu per satu menggunakan media
SMS kepada peserta calon Aslab. Dalam segi waktu, prosesnya membutuhkan banyak waktu serta ada kemungkinan panitia mengirimkan ke nomor yang salah.

Pada penelitian kali ini, peneliti berusaha untuk memberikan solusi untuk menyelesaikan beberapa permasalahan utama di atas. Pemilihan solusi memindahkan beberapa proses manual rekrutmen ke dalam bentuk mobile application memiliki alasan utama yaitu karena mobile application menjadi media yang sudah sangat familiar di kalangan mahasiswa. Jadi seharusnya dengan membuat aplikasi rekrutmen Aslab berbasis mobile bisa sangat memudahkan bagi peserta calon Aslab dalam mengikuti setiap tahapan pada proses rekrutmen nya.

\section{Tinjauan Pustaka}

\subsection{Data dan Informasi}

Menurut Abdul Kadir, data adalah deskripsi tentang benda, kejadian, aktivitas, dan transaksi yang tidak mempunyai makna atau tidak berpengaruh secara langsung kepada pemakai [1], [2]. Data akan menjadi bahan dalam suatu proses pengolahan data, prosesnya terbagi tiga seperti di bawah ini.

a. Tahapan Input Pada tahapan ini merupakan proses memasukan data ke dalam komputer

b. Tahapan Processing Pada tahapan ini melakukan proses mengolah data yang telah dimasukan pada tahapan sebelumnya. Tahapan ini dapat berupa proses perhitungan, perbandingan, ataupun pencarian.

c. Tahapan Output 
Pada tahapan ini merupakan proses menghasilkan keluaran dari hasil pengolahan dari tahapan sebelumnya.

Berdasarkan pada buku Abdul Kadir [2], terdapat beberapa definisi informasi:

a. McFadden, dkk mendefinisikan informasi sebagai data yang telah diproses, sehingga dapat meningkatkan pengetahuan seseorang yang menggunakan data tersebut.

b. Shannon dan Weaver, informasi merupakan jumlah ketidakpastian yang dikurangi ketika sebuah pesan diterima. Dengan begitu, dengan adanya informasi, tingkat kepastian menjadi meningkat.

c. Menurut Davis, informasi adalah data yang telah diolah yang menjadi sebuah bentuk yang berarti bagi penerimanya dan bermanfaat dalam pengambilan keputusan.

\subsection{Aplikasi Mobile}

Seperti pada gambar 1, aplikasi Mobile sederhana memiliki tiga logical layer [3]. Application Layer (Tingkat teratas) merupakan antarmuka komunikasi, dengan begitu pengguna dapat berinteraksi dengan perangkat selularnya. Programmer menggunakan Application Programming Interfaces (API) untuk dapat berkomunikasi dengan Mobile Platform Layer.

Mobile Platform atau disebut juga lapisan tengah merupakan Sistem Operasi yang memiliki banyak fungsi agar dapat berkomunikasi dengan perangkat keras yang ada. Lapisan terakhir, yaitu lapisan perangkat keras yang merupakan perangkat keras pada perangkat yang digunakan untuk berkomunikasi seperti kamera, GPS, dan sebagainya.

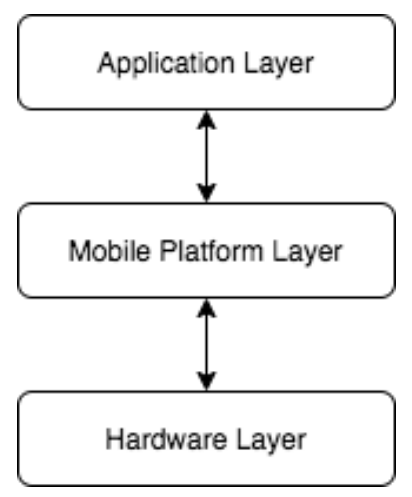

Gambar 1 Lapisan Mobile

\subsection{REST API}

REST API (Representational State Transfer) yang pertama kali dijelaskan oleh Roy Fielding [4] pada Disertasinya adalah salah satu jenis web service yang menerapkan konsep perpindahan antar state. State disini dapat digambarkan seperti jika browser meminta suatu halaman web, maka server akan mengirimkan state halaman web yang sekarang ke browser. Bernavigasi melalui link-link yang disediakan sama halnya dengan mengganti state dari halaman web. Begitu pula REST bekerja, dengan bernavigasi melalui link-link HTTP untuk melakukan aktivitas tertentu, seakan-akan terjadi perpindahan state satu sama lain. Perintah HTTP yang bisa digunakan adalah fungsi GET, POST, PUT atau DELETE. Berikut di bawah ini merupakan arsitektur dari REST API.

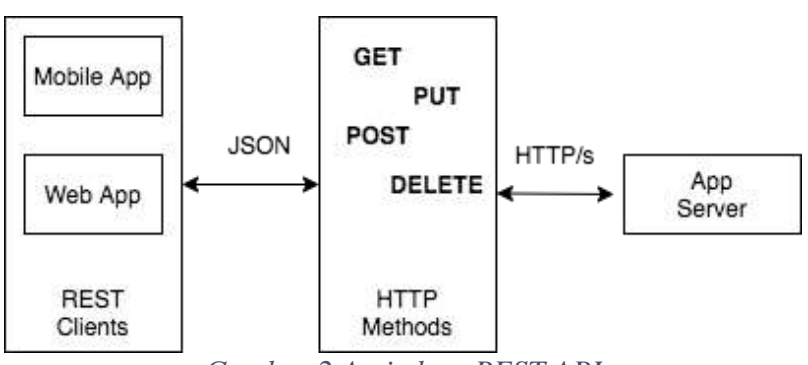

Gambar 2 Arsitektur REST API

\section{Metodologi}

Dalam pengembangan sistem diperlukan suatu metode perancangan yang digunakan untuk menghasilkan sistem yang diharapkan. metode perancangan yang digunakan adalah paradigma prototype model. Model ini mengusulkan sebuah pendekatan kepada pengembangan perangkat lunak yang sistematik dan iteratif yang mulai dari tingkat kemajuan sistem pada seluruh analisis, desain, kode, pengujian dan pemeliharaan. Metode Prototype ini dapat membantu pengembang dalam memahami lebih baik apa yang akan dikembangkan saat spesifikasi kebutuhan belum jelas, sehingga pengembangan aplikasi menjadi lebih mudah karena pengguna mengetahui apa yang diharapkannya [5].

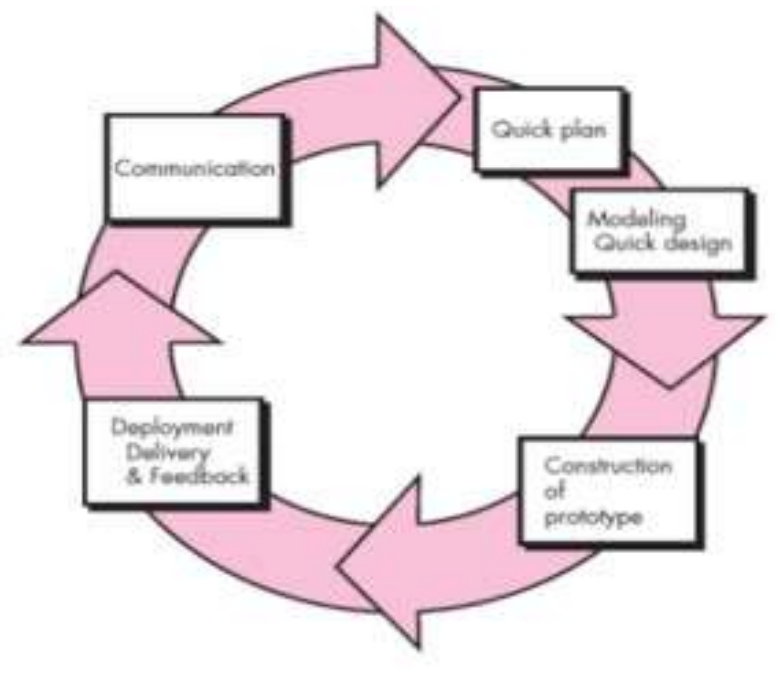

Gambar 3 Model Prototype

a. Communications

Pada tahan komunikasi, peneliti melakukan konsultasi dengan Koordinator Laboratorium dan mencari informasi mengenai proses pengiriman berkas persyaratan saat ini. Mencari informasi bagaimana pihak coordinator dan asisten dalam membuat penjadwalan tahapan rekrutmen hingga proses pemberitahuan hasil akhir penerimaan hingga informasi tersebut sampai ke calon Aslab.

b. Quick Plan

Melakukan perencanaan penelitian yang diambil berdasarkan studi kasus memastikan hal apa yang harus dilakukan untuk dapat menyelesaikan masalah pada studi 
kasus dan mencari teknologi yang tepat untuk dapat diimplementasikan pada studi kasus tersebut.

\section{c. Modeling Quick Design}

Membuat perancangan awal terhadap system yang akan dibuat. Perancangan harus memenuhi dari kebutuhan yang telah di dapat dari informasi pada tahapan sebelumnya.

\section{d. Construction of Prototype}

Pada tahapan ini, mulai membangun aplikasi sesuai dengan perancangan di tahapan sebelumnya. Aplikasi yang dibuat belum sepenuhnya jadi, karena harus dicek kembali dengan kebutuhan pengguna.

e. Deployment Delivery and Feedback

Aplikasi diujikan kepada pengguna langsung, dengan mencari apakah kebutuhan sudah terpebuhi atau belum. Artinya, jika belum terpenuhi fase prototype akan berulang ke fase awal.

\section{Hasil dan Pembahasan}

Perancangan sistem aplikasi rekrutmen Aslab menggunakan UML (Unified Modeling Language) yang dimulai dengan pembuatan skenario-skenario dalam bentuk use-case, activity diagram, swimlane diagram, dan class diagram [5].

\subsection{Arsitektur Sistem}

Sistem rekrutmen Aslab terdiri dari dua bagian, yaitu arsitektur Mobile sistem dan arsitektur Web sistem. Pengguna utama yaitu calon Aslab menggunakan arsitektur Mobile system, sedangkan panitia rekrutmen menggunakan arsitektur sistem yang berbasis Web.

Untuk Web sistem, arsitektur dibuat seperti halnya aplikasi Web. User melakukan request ke aplikasi Web, Web menerima permintaan request dari User lalu melakukan proses permintaan tersebut, mengambil data dari basis data sesuai dengan permintaan. Setelah itu Aplikasi mengirimkan kembali hasil permintaan sebagai Response.

Untuk perangkat mobile, tidak bisa langsung mengakses ke aplikasi Web. Dengan menggunakan REST API yang berfungsi sebagai jembatan proses Request maupun menerima Responses ke Aplikasi utama dapat terjadi dengan baik. Data yang diminta dengan data yang dikirimkan akan tetap sama dengan data yang tersedia di aplikasi utama.

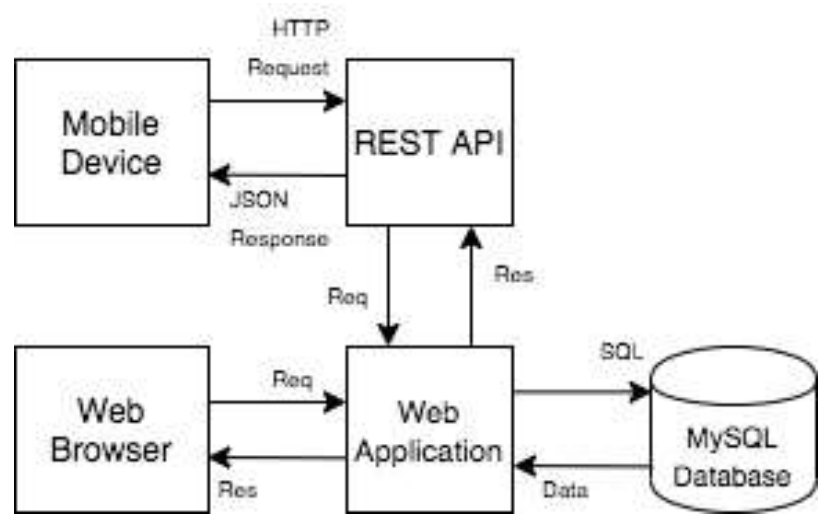

Gambar 4 Arsitektur Sistem

\subsection{Aktor}

Aktor merupakan representasi orang, device, sistem lain yang menggunakan sistem dan memiliki sifat serta fungsi yang dijelaskan dalam sebuah konteks yang memiliki peran terhadap sistem yang akan dibangun.

Tabel 1 Daftar Aktor

\begin{tabular}{|l|l|}
\hline \multicolumn{1}{|c|}{ Aktor } & \multicolumn{1}{c|}{ Keterangan } \\
\hline Admin & $\begin{array}{l}\text { Orang yang mengelola } \\
\text { system }\end{array}$ \\
\hline Client & $\begin{array}{l}\text { Orang yang mengunjungi } \\
\text { sistem }\end{array}$ \\
\hline
\end{tabular}

\subsection{Use-Case Diagram}

Berdasarkan Tabel 4, hanya ada satu aktor yang dapat mengakses sistem. Admin memiliki tugas mengelola sistem secara keseluruhan, sementara pengunjung hanya dapat mengunjungi beberapa use case.

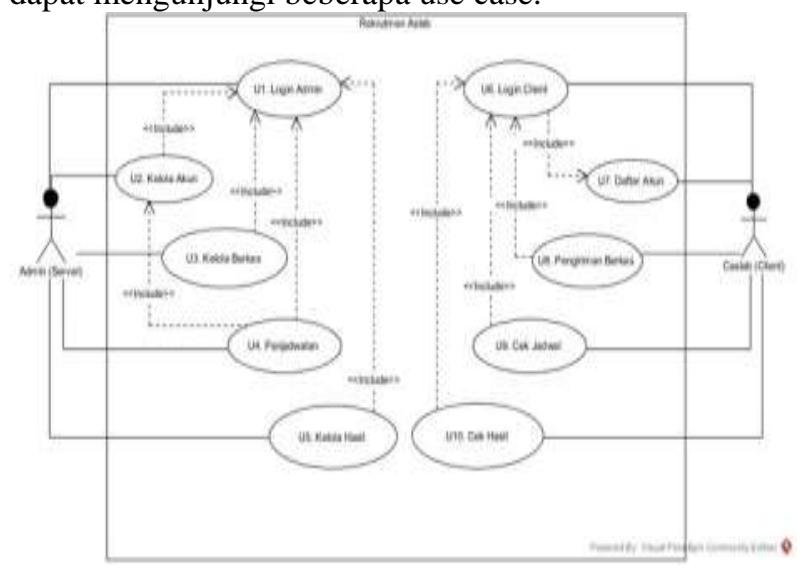

Gambar 5 Use-Case Diagram

Berdasarkan Gambar 5 use case aplikasi rekrutmen Aslab terdapat 10 use case. Jika admin ingin memasuki halaman utama admin dan semua halaman yang ada pada halaman admin, maka harus melakukan login terlebih dahulu agar bisa mengkasesnya. Sedangkan client yang belum memiliki akun harus melakukan daftar akun terlebih dahulu agar dapat mengakses aplikasi rekrutmen.

\subsection{Swimlane Diagram}

Berikut di bawah ini adalah Swimlane Diagram dari aplikasi Rekrutmen Aslab: 
a. Swimlane Diagram Login Admin

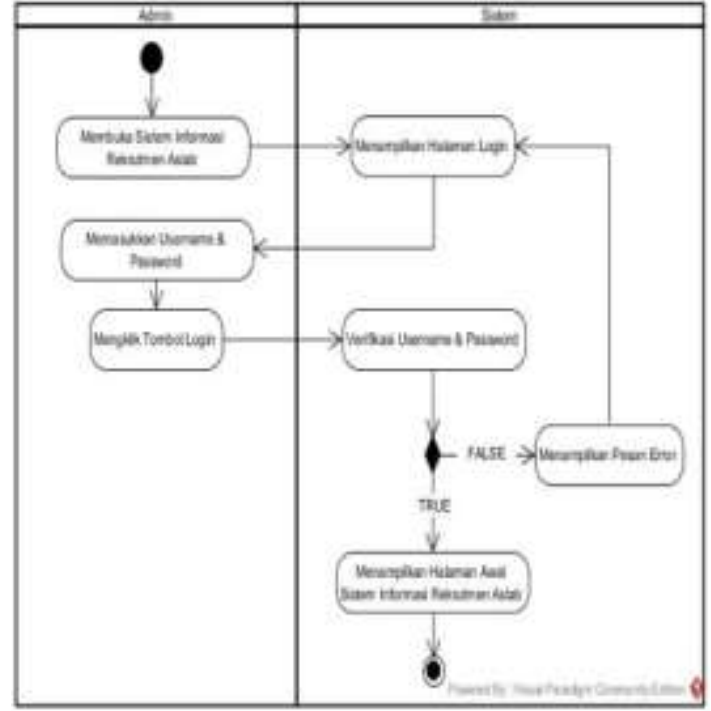

Gambar 6 Swimlane Diagram Login Admin

Berdasarkan Gambar 6 Swimlane Diagram Login menunjukan langkah-langkah aktivitas admin melakukan login agar dapat masuk kedalam halaman utama admin.

b. Swimlane Diagram Penjadwalan

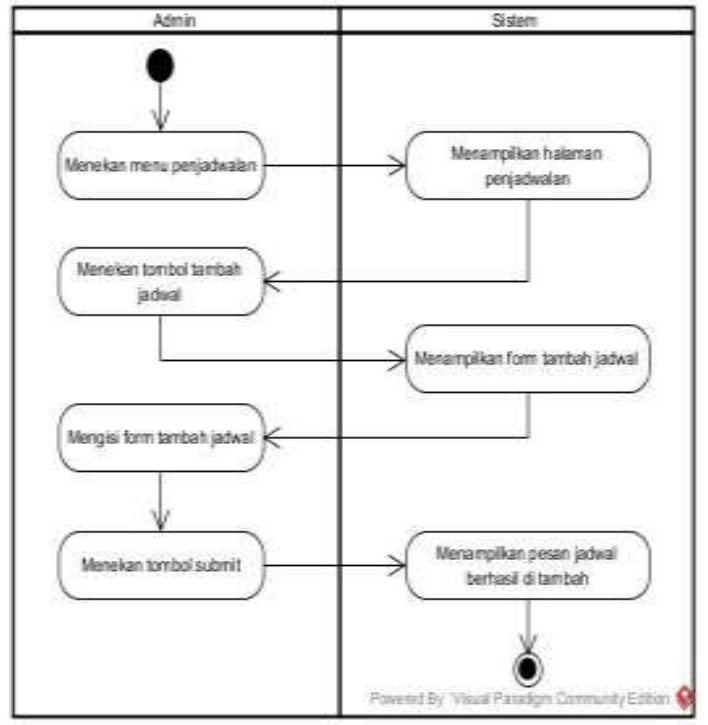

Gambar 7 Swimlane Diagram Penjadwalan

Berdasarkan Gambar 7 Swimlane Diagram Penjadwalan menunjukan aktifitas admin saat mengelola jadwal tahapan rekrutmen calon asisten laboratorium informatika. c. Swimlane Diagram Kelola Hasil

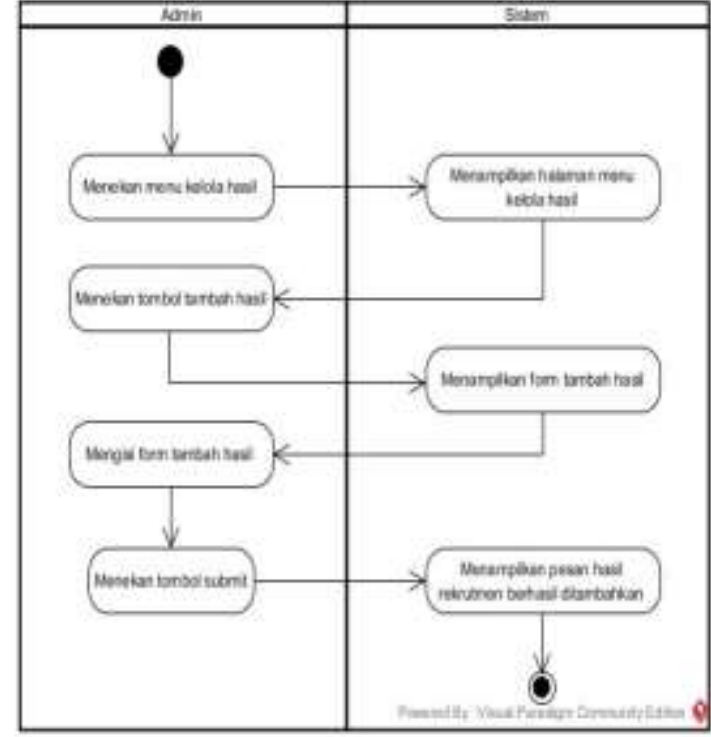

Gambar 8 Swimlane Diagram Kelola Hasil

Berdasarkan Gambar 8 Swimlane Diagram Kelola Hasil menunjukan aktifitas admin saat mengelola hasil penerimaan rekrutmen asisten laboratorium informatika.

d. Swimlane Diagram Login Client

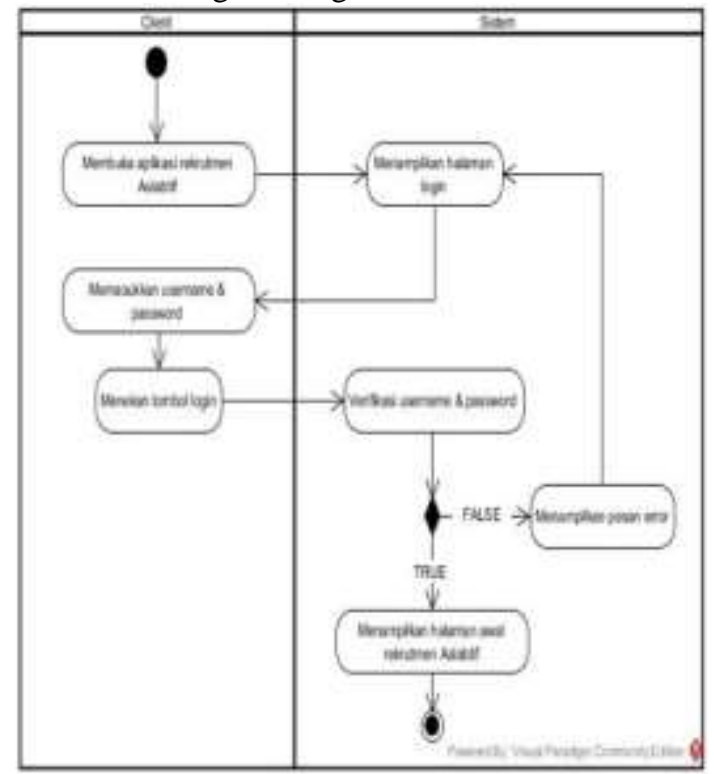

Gambar 9 Swimlane Diagram Login Client

Berdasarkan Gambar 9 Swimlane Diagram Login Client menunjukan langkah-langkah aktivitas client melakukan login agar dapat masuk kedalam halaman utama aplikasi rekrutmen. 
e. Swimlane Diagram Daftar Akun

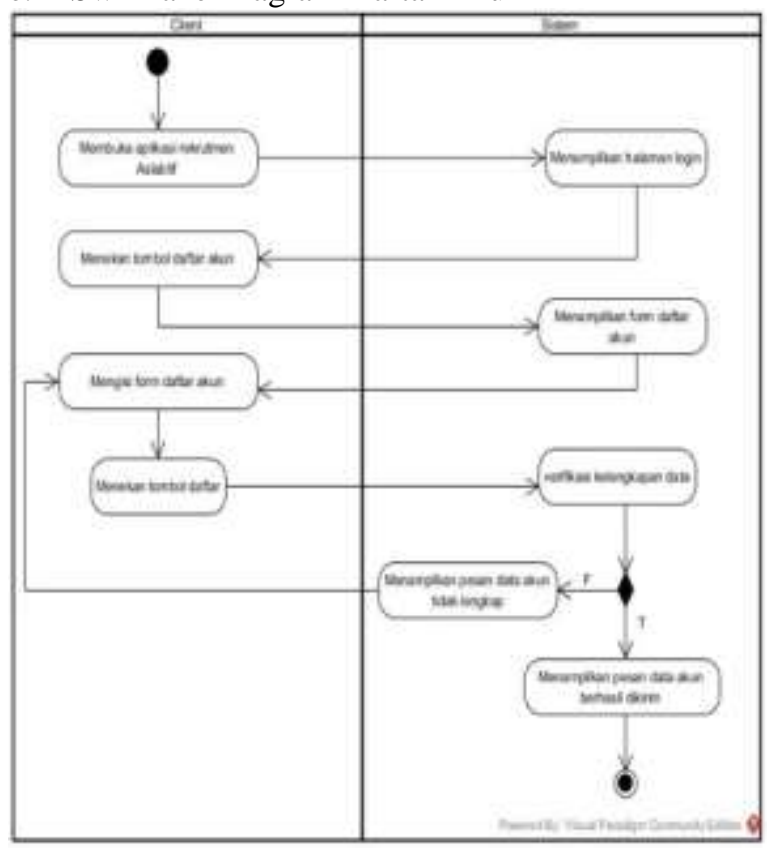

Gambar 10 Swimlane Diagram Daftar Akun

Berdasarkan Gambar 10 Swimlane Diagram Daftar Akun menunjukan aktifitas client saat melakukan pendaftaran akun agar dapat menggunakan aplikasi rekrutmen aslabtif. f. Swimlane Diagram Kirim Berkas

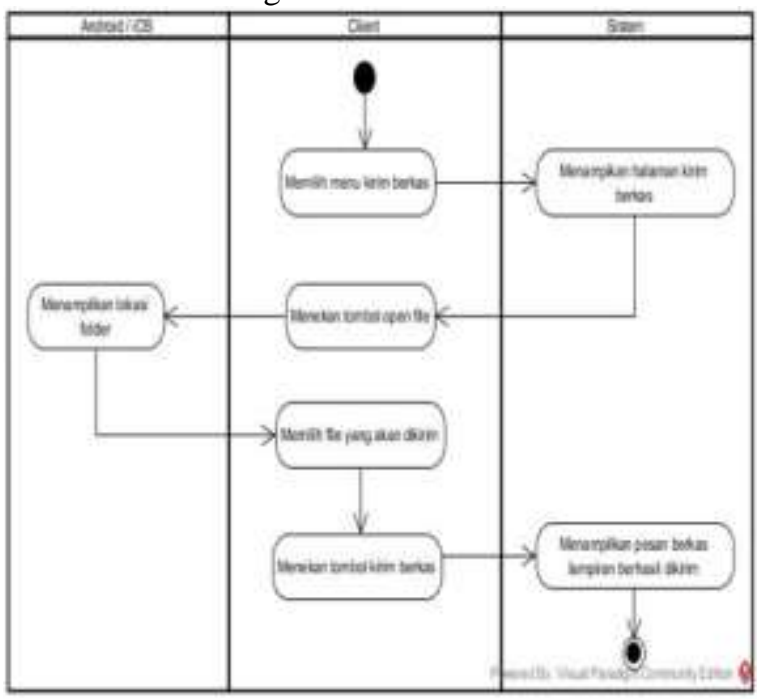

Gambar 11 Swimlane Diagram Kirim Berkas

Berdasarkan Gambar 11 Swimlane Diagram Kirim Berkas menunjukan aktifitas client saat melakukan proses pengiriman berkas persyaratan rekrutmen aslabtif.

\subsection{Class Diagram}

Berikut di bawah ini adalah Class Diagram dari pembuatan aplikasi rekrutmen Aslab: 

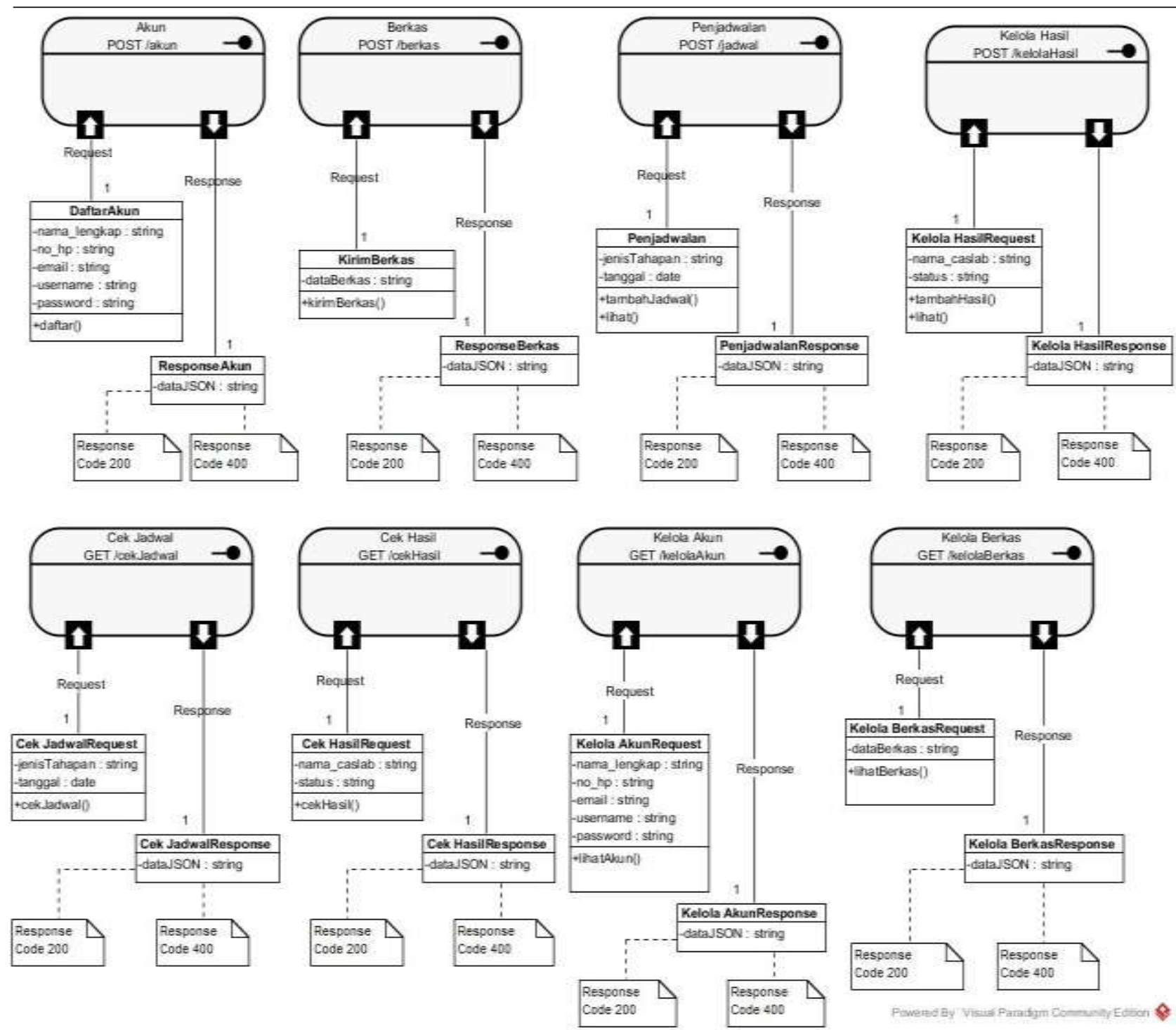

Gambar 12 Class Diagram

Class Diagram REST API Rekrutmen dapat diketahui bahwa Class Diagram tersebut menjelaskan tentang HTTP Verbs yang ada pada REST API tersebut. Request POST dapat dilakukan oleh dua aktor yaitu Client dan Admin, dan request GET juga dapat dilakukan oleh client dan admin. Reqeust POST berhubungan langsung dengan class daftar akun, kirim berkas, penjadwalan, dan kelola hasil. Sedangkan request GET berhubungan langsung dengan class cek jadwal, cek hasil, kelola akun, dan kelola berkas. Response code yang dihasilkan biasanya ada dua, yaitu response code 200 dan 400 .

\subsection{Aplikasi Rekrutmen Aslab}

Aplikasi terbagi menjadi dua bagian, pertama untuk Client yang berbasis Mobile dan kedua Admin sebagai panitia rekrutmen yang berbasis Web. Untuk perangkat Mobile, minimal versi yang digunakan adalah Android Nougat 7.0. Pada tampilan aplikasi di bawah ini dibagi menjadi dua, yaitu Mobile dan Web.
4.6.1 Aplikasi Mobile

a. Login Aplikasi

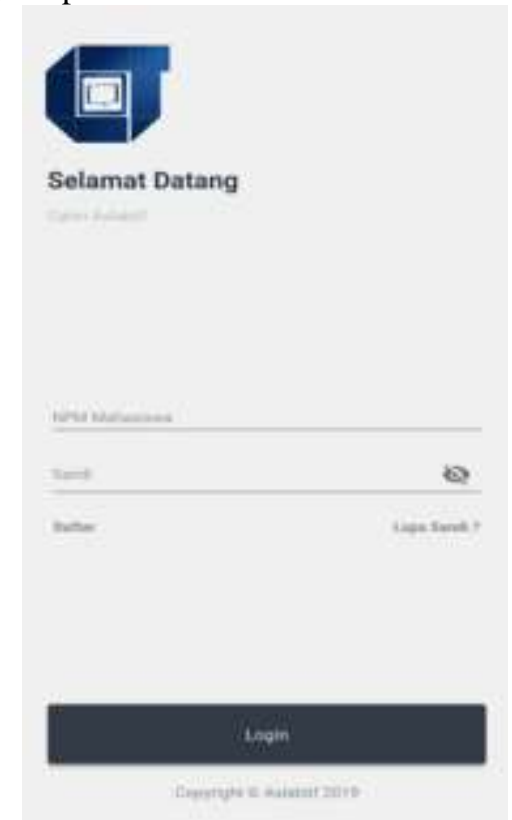

Gambar 13 Login Aplikasi Rekrutmen 
Berdasarkan gambar 13 Login Aplikasi Rekruitmen, sebelum pengguna masuk ke halaman awal pengguna harus login terlebih dahulu dan gambar diatas meruapakan tampilan login aplikasi.

b. Registrasi Akun

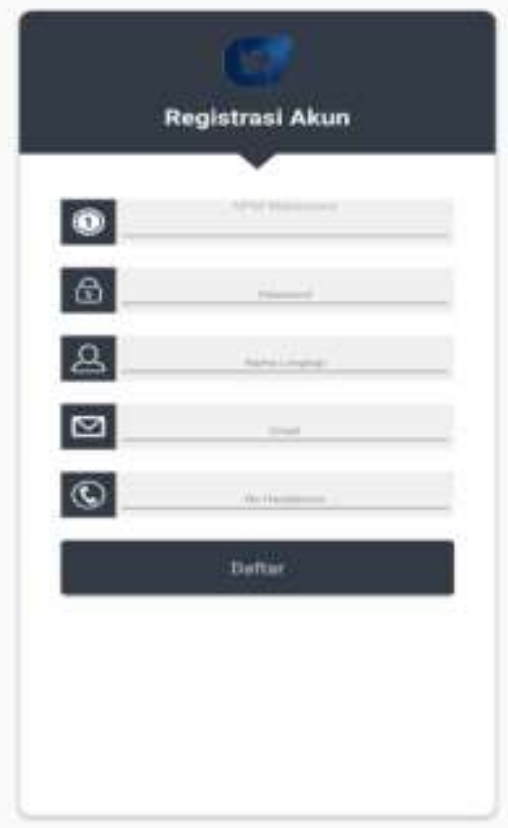

Gambar 14 Registrasi Akun

Berdasarkan gambar 14 Registrasi Akun, jika pengguna belum memiliki akun makan pengguna harus melakukan registrasi akun terlebih dahulu. Gambar diatas merupakan tampilan registrasi akun.

\section{c. Halaman Utama}

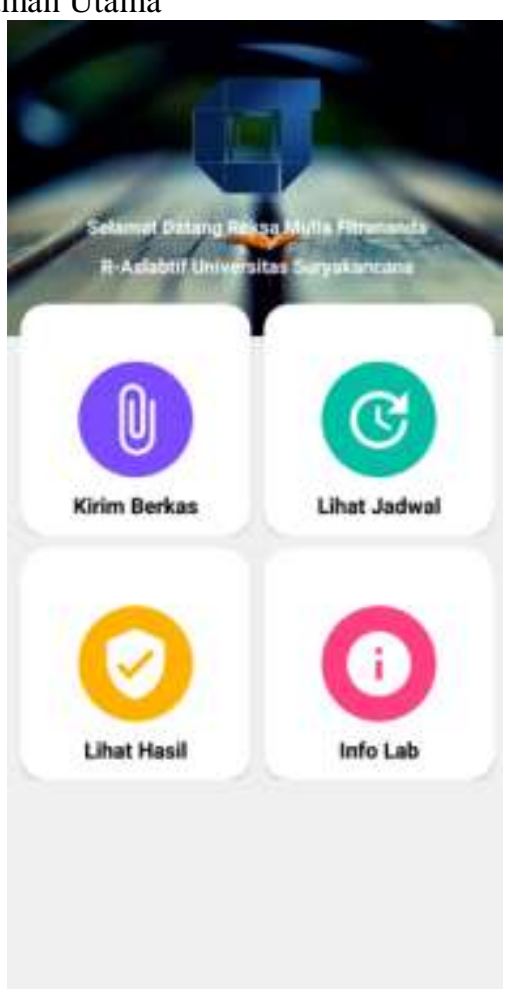

Gambar 15 Halaman Utama Aplikasi
Berdasarkan gambar 15 Halaman Utama Aplikasi Rekruitmen, setelah pengguna berhasil login pengguna akan diarahkan ke halaman utama. Gambar diatas merupakan tampilan halaman utama.

d. Halaman Kirim Berkas

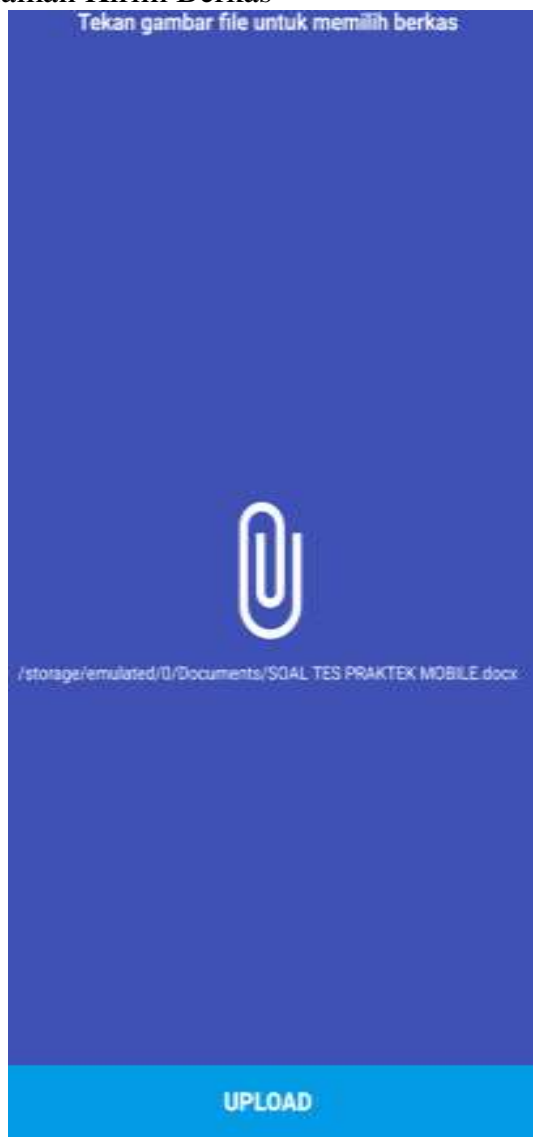

Gambar 16 Halaman Kirim Berkas

Berdasarkan gambar 16 Halaman Kirim Berkas, setelah pengguna berhasil login pengguna akan mengirim berkas persyaratan.

e. Jadwal Proses Rekrutmen

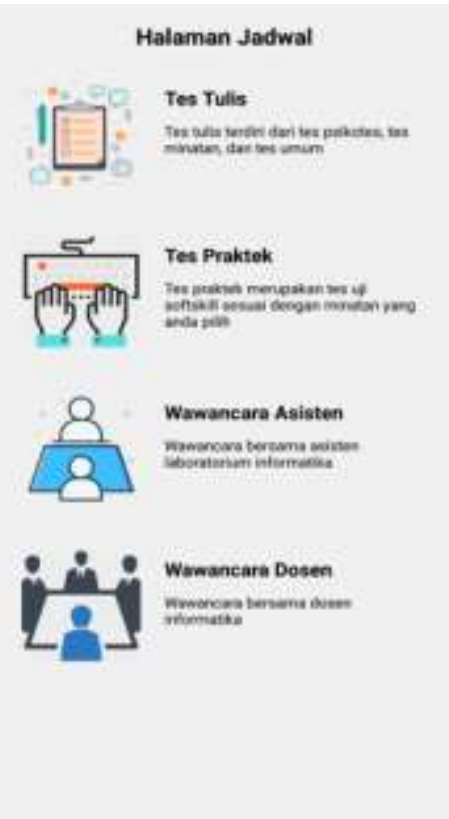

Gambar 17 Tahapan Proses Rekrutmen 
Berdasarkan gambar 17 Tahapan Proses Rekruitmen, pengguna dapat melihat proses rekruitmen. Gambar diatas merupakan tampilan tahapan proses rekruitmen.

\section{f. Jadwal Tes Tulis}

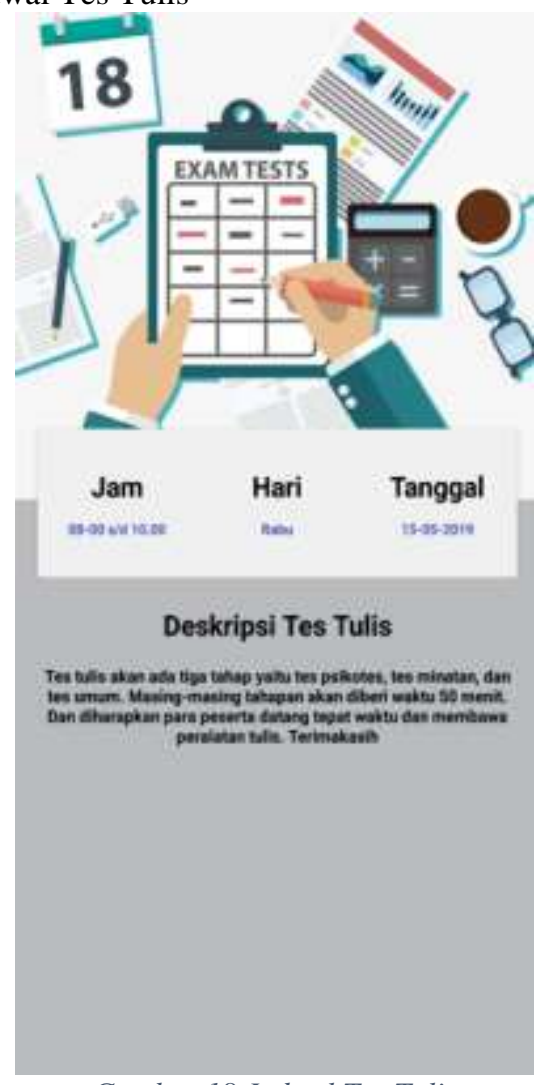

Gambar 18 Jadwal Tes Tulis

Berdasarkan gambar 18 Jadwal Tes Tulis, pengguna dapat melihat jadwal tes tulis dimulai dari jam, hari, dan tanggal. Gambar diatas merupakan tampilan halaman jadwal tes tulis.

\section{g. Cek Hasil Rekrutmen Aslab}

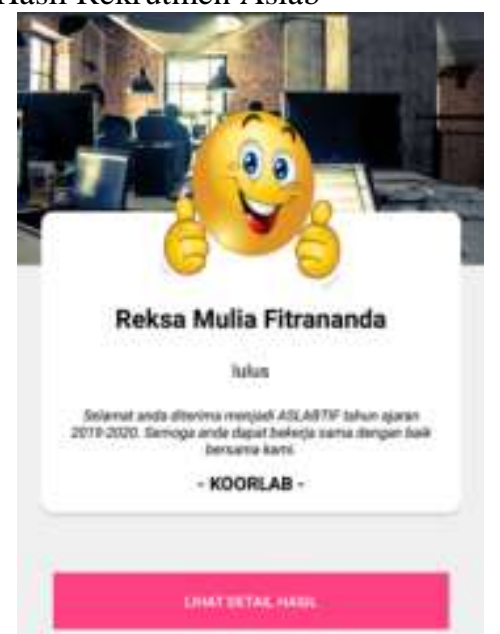

Gambar 19 Cek Hasil Rekrutmen Aslab
Berdasarkan gambar 19 Cek Hasil Rekruitmen, pengguna dapat melihat hasil rekruitmen. Gambar diatas merupakan tampilan halaman cek hasil rekruitmen.

\subsubsection{Aplikasi Web}

a. Login Admin

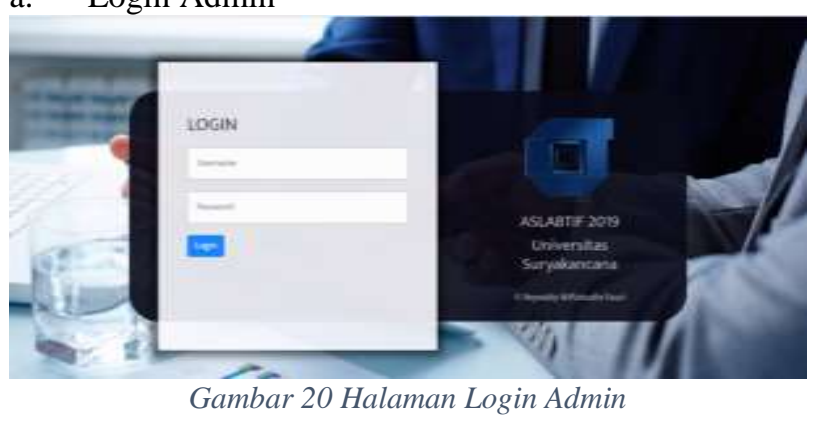

Berdasarkan gambar 20 Halaman Login Admin, sebelum admin dapat masuk ke halaman utama admin harus melakukan login terlebih dahulu.

b. Halaman Utama Admin

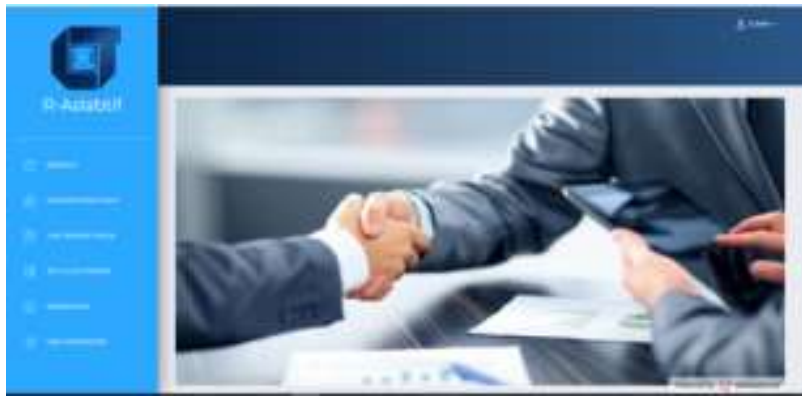

Gambar 21 Halaman Utama Admin

Berdasarkan gambar 21 Halaman Utama Admin, admin yang telah login akan masuk ke halaman utama sistem.

c. Halaman Data Registrasi Akun

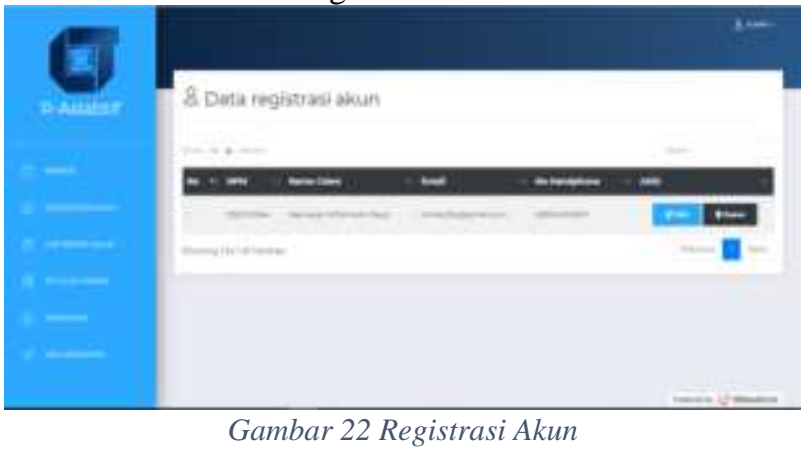

Berdasarkan gambar 22 Halaman Data Registrasi Akun, admin dapat melihat data registrasi akun yang telah masuk ke dalam sistem. 


\section{d. Halaman Jadwal Tes Tulis \& Praktek}

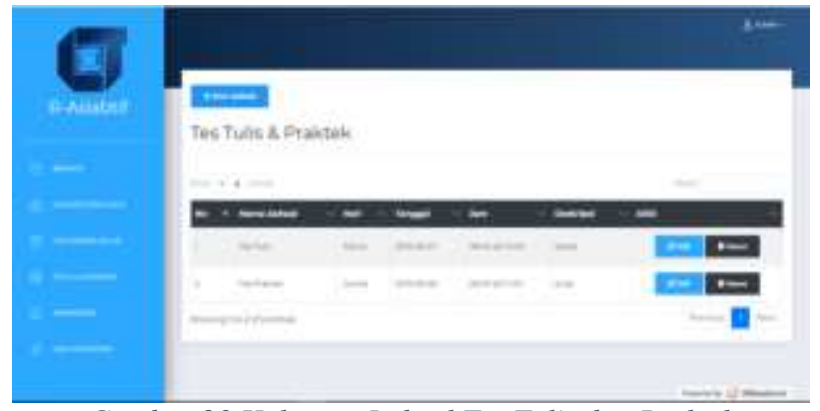

Gambar 23 Halaman Jadwal Tes Tulis dan Praktek

Berdasarkan gambar 23 Halaman Jadwal Tes Tulis \& Praktek, admin dapat menentukan jadwal tes tulis dan tes praktek pada halaman tersebut.

\section{e. Halaman Hasil Rekrutmen}

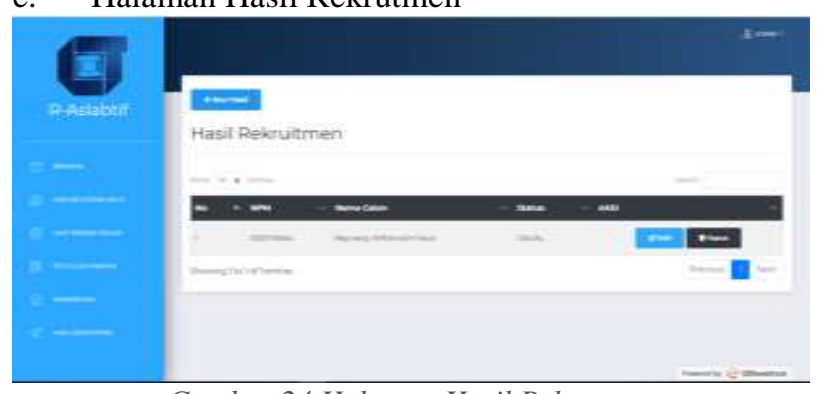

Gambar 24 Halaman Hasil Rekrutmen

\section{f. Halaman Lihat Berkas}

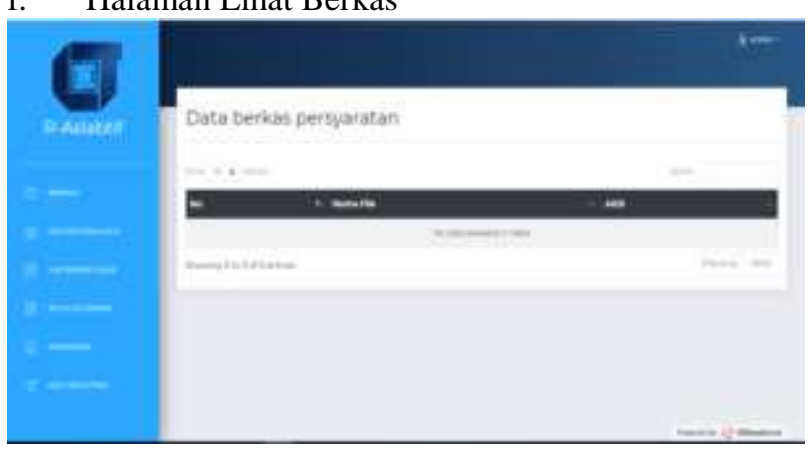

Gambar 25 Lihat Berkas Persyaratan

Berdasarkan gambar 25 Lihat Berkas Persyaratan, admin dapat melihat berkas persyaratan yang telah dikirim oleh calon asisten.

\subsection{Pengujian}

Pengujian merupakan bagian yang penting dalam siklus pengembangan perangkat lunak. Pengujian dilakukan untuk menjamin kualitas dan juga mengetahui kelemahan dari perangkat lunak. Tujuan dari pengujian ini adalah untuk menjamin bahwa perangkat lunak yang dibangun memiliki kualitas yang handal. Pengujian perangkat lunak ini menggunakan metode pengujian Black Box. Pengujian pada aplikasi Rekrutmen Aslab seperti tertera pada Tabel 2.

Berdasarkan gambar 24 Halaman Hasil Rekrutmen, admin dapat menentukan calon asisten yang diterima menjadi Aslab.

\section{Tabel 2 Tabel Pengujian}

\begin{tabular}{|c|c|c|c|}
\hline No & Fungsi & Deskripsi & Kesesuaian \\
\hline 1 & Login Calon Asisten & $\begin{array}{l}\text { Jika username dan password yang dimasukan sesuai maka user akan } \\
\text { diarahkan ke halaman awal aplikasi rekrutmen. Namun jika username } \\
\text { atau password yang user masukan tidak sesuai maka akan muncul pesan } \\
\text { kesalahan. }\end{array}$ & Sesuai \\
\hline 2 & $\begin{array}{l}\text { Kirim file berkas } \\
\text { persyaratan rekrutmen }\end{array}$ & $\begin{array}{l}\text { User yang sudah login memilih menu kirim berkas, setelah itu mengklik } \\
\text { tombol open file. Jika pencarian file selesai maka user mengklik tombol } \\
\text { ok setelah itu user akan menekan tombol kirim. }\end{array}$ & Sesuai \\
\hline 3 & $\begin{array}{l}\text { Cek Jadwal } \\
\text { Rekrutmen }\end{array}$ & $\begin{array}{l}\text { User yang sudah login memilih menu cek jadwal, setelah itu sistem akan } \\
\text { menampilkan list tahapan proses rekrutmen. }\end{array}$ & Sesuai \\
\hline 4 & Cek Hasil Rekrutmen & $\begin{array}{l}\text { User yang sudah login memilih menu cek hasil, setelah itu sistem akan } \\
\text { menampilkan daftar calon yang diterima maupun yang ditolak untuk } \\
\text { menjadi aslab. }\end{array}$ & Sesuai \\
\hline 5 & Cek Info Lab & $\begin{array}{l}\text { User yang sudah login memilih menu lihat info lab, setelah itu sistem } \\
\text { akan menampilkan informasi mengenai laboratorium komputer. }\end{array}$ & Sesuai \\
\hline 6 & Logout Calon Asisten & $\begin{array}{l}\text { User yang sedang berada di halaman utama akan menekan tombol logout } \\
\text { agar dapat keluar dari sistem dan kembali ke halaman login }\end{array}$ & Sesuai \\
\hline 7 & Login Admin & $\begin{array}{l}\text { Jika username dan password yang dimasukan sesuai maka admin akan } \\
\text { diarahkan ke halaman awal sistem. Namun jika username atau password } \\
\text { yang admin masukan tidak sesuai maka akan muncul pesan kesalahan. }\end{array}$ & Sesuai \\
\hline 8 & Kelola Akun & $\begin{array}{l}\text { Admin yang sudah login memilih menu kelola akun dan sistem akan } \\
\text { menampilkan halaman kelola akun. }\end{array}$ & Sesuai \\
\hline 9 & Cari Data Akun & $\begin{array}{l}\text { Admin yang sudah login memilih menu kelola akun, jika ingin mencari } \\
\text { data akun tertentu, admin mengisi kata kunci pencarian pada kolom } \\
\text { pencarian dan halaman kelola akan menampilkan daftar akun yang } \\
\text { sesuai dengan kata kunci pencarian }\end{array}$ & Sesuai \\
\hline 10 & Edit Akun & $\begin{array}{l}\text { Admin yang sudah login memilih menu kelola akun, jika ingin merubah } \\
\text { data akun admin dapat menekan tombol edit. Jika perubahan telah selesai }\end{array}$ & Sesuai \\
\hline
\end{tabular}




\begin{tabular}{|c|c|c|c|}
\hline & & $\begin{array}{l}\text { admin menekan tombol simpan maka data tersebut akan berubah dan } \\
\text { langsung tersimpan ke database. }\end{array}$ & \\
\hline 11 & Hapus Akun & $\begin{array}{l}\text { Admin yang sudah login memilih menu kelola akun, jika ingin } \\
\text { menghapus data akunadmin hanya perlu mengklik tombol hapus dan data } \\
\text { akun tersebut akan terhapus. }\end{array}$ & Sesuai \\
\hline 12 & $\begin{array}{l}\text { Kelola Jadwal Tes } \\
\text { TUlis dan Praktek }\end{array}$ & $\begin{array}{l}\text { Admin yang sudah login memilih menu jadwal tes tulis \& praktek, } \\
\text { setelah itu sistem akan menampilkan halaman jadwal tes tulis \& praktek }\end{array}$ & Sesuai \\
\hline 13 & Tambah Jadwal & $\begin{array}{l}\text { Admin yang sudah login memilih menu kelola tes tulis \& praktek, jika } \\
\text { ingin menambah jadwal tes tulis \& praktek, admin dapat menekan tombol } \\
\text { atur jadwal jika telah selesai melakukan pengisian atur jadwal admin } \\
\text { menekan tombol simpan dan data jadwal akan masuk ke sistem dan juga } \\
\text { database. }\end{array}$ & Sesuai \\
\hline 14 & Edit Jadwal & $\begin{array}{l}\text { Admin yang sudah login memilih menu kelola jadwal tes tulis \& praktek, } \\
\text { jika ingin merubah data jadwal admin dapat menekan tombol edit. Jika } \\
\text { perubahan telah selesai admin menekan tombol simpan maka data } \\
\text { tersebut akan berubah dan langsung tersimpan ke database. }\end{array}$ & Sesuai \\
\hline 15 & Hapus Jadwal & $\begin{array}{l}\text { Admin yang sudah login memilih menu kelola Jadwal tes tulis \& praktek, } \\
\text { jika ingin menghapus data jadwal admin hanya perlu mengklik tombol } \\
\text { hapus dan data jadwal tersebut akan terhapus. }\end{array}$ & Sesuai \\
\hline 16 & Cari Jadwal & $\begin{array}{l}\text { Admin yang sudah login memilih menu kelola jadwal tes tulis \& praktek, } \\
\text { jika ingin mencari data testimoni tertentu, admin mengisi kata kunci } \\
\text { pencarian pada kolom pencarian dan halaman kelola jadwal akan } \\
\text { menampilkan daftar jadwal yang sesuai dengan kata kunci pencarian. }\end{array}$ & Sesuai \\
\hline 17 & $\begin{array}{l}\text { Kelola Jadwal } \\
\text { Wawancara }\end{array}$ & $\begin{array}{l}\text { Admin yang sudah login memilih menu kelola jadwal wawancara, setelah } \\
\text { itu sistem akan menampilkan halaman jadwal wawancara. }\end{array}$ & Sesuai \\
\hline 18 & $\begin{array}{l}\text { Tambah Jadwal } \\
\text { Wawancara }\end{array}$ & $\begin{array}{l}\text { Admin yang sudah login memilih menu kelola jadwal wawancara, setelah } \\
\text { itu mengklik tombol tambah jadwal. Jika pengisian selesai maka admin } \\
\text { mengklik tombol simpan dan data akan tersimpan di database dan } \\
\text { halaman kelola jadwal wawancara akan menampilkan daftar jadwal } \\
\text { wawancara tiap calon asisten. }\end{array}$ & Sesuai \\
\hline 19 & $\begin{array}{l}\text { Edit Jadwal } \\
\text { Wawancara }\end{array}$ & $\begin{array}{l}\text { Admin yang sudah login memilih menu kelola jadwal wawancara, setelah } \\
\text { itu mengklik tombol edit. Jika perubahan selesai maka admin mengklik } \\
\text { tombol simpan dan data akan tersimpan di database dan halaman kelola } \\
\text { jadwal wawancara akan menampilkan daftar jadwal wawancara tiap } \\
\text { calon asisten. }\end{array}$ & Sesuai \\
\hline 20 & $\begin{array}{l}\text { Hapus Jadwal } \\
\text { Wawancara }\end{array}$ & $\begin{array}{l}\text { Admin yang sudah login memilih menu kelola jadwal wawancara, jika } \\
\text { ingin menghapus jadwal wawancara admin hanya perlu mengklik tombol } \\
\text { hapus dan data jadwal tersebut akan terhapus. }\end{array}$ & Sesuai \\
\hline 21 & $\begin{array}{l}\text { Cari Jadwal } \\
\text { Wawancara }\end{array}$ & $\begin{array}{l}\text { Admin yang sudah login memilih menu kelola jadwal wawancara, jika } \\
\text { ingin mencari jadwal wawancara tertentu, admin mengisi kata kunci } \\
\text { pencarian pada kolom pencarian dan halaman kelola jadwal wawancara } \\
\text { akan menampilkan daftar jadwal wawancara yang sesuai dengan kata } \\
\text { kunci pencarian. }\end{array}$ & Sesuai \\
\hline 22 & $\begin{array}{l}\text { Kelola Hasil } \\
\text { Rekrutmen }\end{array}$ & $\begin{array}{l}\text { Admin yang sudah login memilih menu kelola jadwal wawancara, setelah } \\
\text { itu sistem akan menampilkan halaman jadwal wawancara. }\end{array}$ & Sesuai \\
\hline 23 & $\begin{array}{l}\text { Tambah Hasil } \\
\text { Rekrutmen }\end{array}$ & $\begin{array}{l}\text { Admin yang sudah login memilih menu kelola hasil rekrutmen, setelah } \\
\text { itu mengklik tombol tambah hasil. Jika pengisian selesai maka admin } \\
\text { mengklik tombol simpan dan data akan tersimpan di database dan } \\
\text { halaman kelola hasil rekrutmen akan menampilkan daftar hasil rekrutmen } \\
\text { tiap calon asisten. }\end{array}$ & Sesuai \\
\hline 24 & Edit Hasil Rekrutmen & $\begin{array}{l}\text { Admin yang sudah login memilih menu kelola hasil rekrutmen, setelah } \\
\text { itu mengklik tombol edit. Jika perubahan selesai maka admin mengklik } \\
\text { tombol simpan dan data akan tersimpan di database dan halaman kelola } \\
\text { hasil rekrutmen akan menampilkan daftar hasil rekrutmen tiap calon } \\
\text { asisten }\end{array}$ & Sesuai \\
\hline 25 & $\begin{array}{l}\text { Hapus Hasil } \\
\text { Rekrutmen }\end{array}$ & $\begin{array}{l}\text { Admin yang sudah login memilih menu kelola hasil rekrutmen, jika ingin } \\
\text { menghapus hasil rekrutmen admin hanya perlu mengklik tombol hapus } \\
\text { dan data hasil rekrutmen tersebut akan terhapus. }\end{array}$ & Sesuai \\
\hline
\end{tabular}




\section{Kesimpulan}

Dari hasil penelitian ini dapat disimpulkan bahwa aplikasi ini dapat memudahkan para mahasiswa calon Aslab melakukan pendaftaran rekrutmen Aslab. Dengan menggunakan aplikasi ini, peserta tidak lagi harus datang menyerahkan berkas karena pengiriman berkas bias melalui aplikasi. Tahapan rekrutmen pun dapat dicek melalui aplikasi seperti jadwal dan hasil rekrutmen. Yang menjadi pengembangan ke depan adalah sistem ini seharusnya dapat diintegrasikan dengan sistem manajemen laboratorium yang sedang berjalan.

\section{Daftar Pustaka}

[1] F. Nurpandi and H. Kurniawan, "Sistem Informasi Pembudidayaan Ikan di Balai Pelestarian Perikanan Perairan Umum Dan Pengembangan Ikan Hias ( BPPPUIH ) Ciherang - Cianjur," Media J. Inform., vol. 8, no. 2, pp. 69-79, 2016.

[2] A. Kadir, Pengenalan Sistem Informasi Edisi Revisi. Yogyakarta: Andi Publisher, 2014.

[3] S. A. Gadhiya, K. H. Wandra, and V. B. Vaghela, "Role of mobile augmentation in mobile application development," AICERA 2012 - Annu. Int. Conf. Emerg. Res. Areas Innov. Pract. Futur. Trends, 2012.

[4] R. T. Fielding, "Architectural Styles and the Design of Network-based Software Architectures," University of California, Irvine, 2000.

[5] R. S. Pressman, Software Engineering A Practitioner's Approach 8th Edition. New York: McGraw-Hill Education, 2015. 